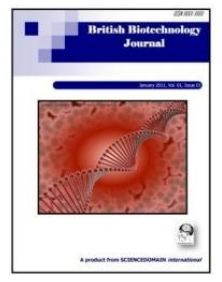

British Biotechnology Journal

6(2): 87-92, 2015, Article no.BBJ.2015.030

ISSN: 2231-2927

SCIENCEDOMAIN international

www.sciencedomain.org

\title{
Genetic and Phenotypic Identification of Vancomycin-Resistant Staphylococcus aureus Isolates from Retail Poultry Carcasses in Omu-Aran, North-Central Nigeria
}

\author{
C. E. Okolie ${ }^{1 *}$, U. C. Essien ${ }^{2}$ and J. Idoko \\ ${ }^{1}$ Department of Biological Sciences, Landmark University, Omu-Aran, Kwara State, Nigeria. \\ ${ }^{2}$ Department of Medical Laboratory Sciences, University of Jos, Plateau State, Nigeria. \\ ${ }^{3}$ Department of Histopathology and Cytology, Ahmadu Bello University, Teaching Hospital, Zaria, \\ Kaduna State, Nigeria.
}

Authors' contributions

This work was carried out in collaboration between all authors. Author CEO designed the study, wrote

the protocol, and wrote the first draft of the manuscript. Authors CEO, UCE and JI managed the analyses of the study. All authors performed the wet laboratory experiments and statistical analysis, read and approved the final manuscript.

Article Information

DOI: $10.9734 / \mathrm{BBJ} / 2015 / 13145$

(1) Chan Yean Yean, Department of Medical Microbiology and Parasitology, School of Medical Sciences, Universiti Sains Malaysia, Malaysia. Reviewers:

(1) Anonymous, Kenya

(2) Anonymous, Egypt.

Complete Peer review History: http://www.sciencedomain.org/review-history.php?iid=806\&id=11\&aid=8040

Original Research Article

Received $5^{\text {th }}$ August 2014 Accepted $8^{\text {th }}$ September 2014 Published $5^{\text {th }}$ February 2015

\section{ABSTRACT}

Staphylococcus aureus is a well-known agent of zoonotic infections. Livestock-associated methicillin-resistant $S$. aureus (LA-MRSA) had been receiving public health attention for over a decade. Recently, the genomes of some MRSA strains evolved further by enabling acquisition of vanA gene from enterococcus which drives the emergence of vancomycin-resistant $S$. aureus (VRSA), thus signaling a higher threat to antimicrobial chemotherapy and diagnostic microbiology. This study was designed to examine slaughtered chicken carcasses in Omu-Aran, North-Central Nigeria for the presence of VRSA using vancomycin agar screen (VAS) as recommended by the Clinical and Laboratories Standards Institute (CLSI). To provide independent witness to further support the evidences from VAS, a 235 bp marker for vanA gene was simultaneously detected by 
PCR. From April 2013 through May 2014, chicken carcasses $(n=784)$ were collected and studied. Among 155 (19.8\%) samples which yielded S. aureus, VAS and vanA PCR methods unequivocally identified VRSA in 22 (14.2\%). Compared with 46.2\% VRSA report from Zaria, North-Western Nigeria, the incidence of VRSA is much less in Omu-Aran chicken carcasses than those of Zaria. Further investigation in other parts of Nigeria is recommended in order to generate nation-wide data on VRSA in this country.

Keywords: Staphylococcus aureus; poultry; VRSA; PCR; vancomycin agar screen.

\section{INTRODUCTION}

The evolution of antimicrobial resistant clones in bacteria including the staphylococci is impacting adversely on humans as well as on domesticated animals. Especially interesting is the widespread methicillin resistant Staphylococcus aureus (MRSA) strains some of which recently evolved further into vancomycin resistant $S$. aureus (VRSA). Several reports have provided evidences for the mechainism of acquisition of $m e c A$ gene which drives MRSA as prerequisite to the acquisition via horizontal gene transfer (HGT) of vanA gene which encodes staphylococcal vancomycin resistance [1-3]. While the world battles the menace visited upon public health by HGT-associated resistance to antibiotics, the recent report of MRSA which transformed into VRSA within the same patient [4] makes the story of VRSA more complex than MRSA.

Expert reviews have highlighted the need for correct identification of the genetic capacity for and expression of vancomycin resistance in staphylococcal isolates $[5,6]$. Also, given the high chances of inter-species transmission, livestockassociated $S$. aureus should not be seen as very distant from humans. Furthermore, the frequency of VRSA in domesticated animals should be seen as an emerging threat to food security. The Food and Agricultural Organization (FAO) estimated that domesticated birds in Nigeria with a population of 140 million supplies about one billion eggs and 500,000 metric tons of poultry meat annually [7]. The poultry industry obviously makes meaningful input to Nigeria's economy. Recently we isolated VRSA during routine testing of poultry and human specimens in Omu-Aran. In addition to this new finding, the possibility of emission via the airborne route [8] and there cent report of high prevalence of VRSA among poultry $S$. aureus in Zaria, North-Western Nigeria [9] all informed our interest in investigating chickens in Omu-Aran, North-Central Nigeria for VRSA by random sampling of retail carcasses.

\section{MATERIALS AND METHODS}

\subsection{Control Bacterial Strains Used in this Study}

Bacterial strains used as controls for this study are listed (Table 1). They include recently isolated strains of VRSA $(n=2)$ harbouring the vanA gene and used as PCR positive controls for the gene detection assay as well as the vancomycin agar screen (VAS) method. Coagulase-negative staphylococcus (CoNS) strains $(n=24)$ and vancomycin-susceptible $S$. aureus (VSSA) strains $(n=22)$ were used as negative controls.

\subsection{Sample Population Size}

Chicken carcasses $(n=784)$ were examined over a period of fourteen months (April 2013 through May 2014). They were obtained at slaughter from the poultry section of Omu-Aran abattoir in New Market, Sabo, Omu-Aran.

\subsection{Sample Collection and Transportation}

Following the method of Persoons et al. [10], chicken parts were placed in a disposable sterile bag containing $400 \mathrm{~mL}$ of brain-heart infusion $(\mathrm{BHI})$ broth supplemented with nalidixic acid and colistin each at a concentration of $10 \mu \mathrm{g} / \mathrm{mL}$. At the end of each day of sample collection, all collected samples were transported to the laboratory which is less than 30 minutes away.

\subsection{Isolation and Identification of Staphylococcus aureus in Samples}

Following overnight incubation of the broth at room temperature $\left(30^{\circ} \mathrm{C}\right)$, an aliquot $(10.0 \mu \mathrm{L})$ was streak-inoculated unto a $\mathrm{BH}$ plate containing $4 \% \mathrm{NaCl}$ and incubated overnight at $35^{\circ} \mathrm{C}$. Based on colonial appearance, discrete colonies suspected to be staphylococci were subjected to conventional identification procedures including Gram staining, catalase, and coagulase tests. 
Table 1. Characteristics of control bacterial strains ( $n=48)$ used for this study ${ }^{a}$

\begin{tabular}{|c|c|c|}
\hline $\begin{array}{l}\text { Strain } \\
\text { identity }\end{array}$ & $\begin{array}{l}\text { Type of } \\
\text { staphylococcus } \\
\text { (CoNS, S. aureus } \\
\text { or VRSA) }\end{array}$ & vanA gene $^{b}$ \\
\hline Omu-SA1 & S. aureus & - \\
\hline Omu-SA2 & S. aureus & - \\
\hline Omu-SA3 & S. aureus & - \\
\hline Omu-SA4 & S. aureus & - \\
\hline Omu-SA5 & S. aureus & - \\
\hline Omu-SA6 & S. aureus & - \\
\hline Omu-SA7 & S. aureus & - \\
\hline Omu-SA8 & S. aureus & - \\
\hline Omu-SA9 & S. aureus & - \\
\hline Omu-SA10 & S. aureus & - \\
\hline Omu-SA11 & S. aureus & - \\
\hline Omu-SA12 & S. aureus & - \\
\hline Omu-SA13 & S. aureus & - \\
\hline Omu-SA14 & S. aureus & - \\
\hline Omu-SA15 & S. aureus & - \\
\hline Omu-SA16 & S. aureus & - \\
\hline Omu-SA17 & S. aureus & - \\
\hline Omu-SA18 & S. aureus & - \\
\hline Omu-SA19 & S. aureus & - \\
\hline Omu-SA20 & S. aureus & - \\
\hline Omu-SA21 & S. aureus & - \\
\hline Omu-SA22 & S. aureus & - \\
\hline Omu-VRSA1 & VRSA & + \\
\hline Omu-VRSA2 & VRSA & + \\
\hline Omu-CoNs1 & CoNS & - \\
\hline Omu-CoNS2 & CoNS & - \\
\hline Omu-CoNS3 & CoNS & - \\
\hline Omu-CoNS4 & CoNS & - \\
\hline Omu-CoNS5 & CoNS & - \\
\hline Omu-CoNS6 & CoNS & - \\
\hline Omu-CoNS7 & CoNS & - \\
\hline Omu-CoNS8 & CoNS & - \\
\hline Omu-CoNS9 & CoNS & - \\
\hline Omu-CoNS10 & CoNS & - \\
\hline Omu-CoNS11 & CoNS & - \\
\hline Omu-CoNS12 & CoNS & - \\
\hline Omu-CoNS13 & CoNS & - \\
\hline Omu-CoNS14 & CoNS & - \\
\hline Omu-CoNS15 & CoNS & - \\
\hline Omu-CoNS16 & CoNS & - \\
\hline Omu-CoNS17 & CoNS & - \\
\hline Omu-CoNS18 & CoNS & - \\
\hline Omu-CoNS19 & CoNS & - \\
\hline Omu-CoNS20 & CoNS & - \\
\hline Omu-CoNS21 & CoNS & - \\
\hline Omu-CoNS22 & CoNS & - \\
\hline Omu-CoNs23 & CoNS & - \\
\hline Omu-CoNs24 & CoNS & - \\
\hline
\end{tabular}

\subsection{Phenotypic Detection of VRSA by Vancomycin Agar Screen (VAS) Method}

The Clinical and Laboratory Standards Institute (CLSI) recommended vancomycin agar screen (VAS) for identification of VRSA [11]. Briefly, vancomycin supplement (Oxoid, Basingstoke, UK) was incorporated into BHlagar to a concentration of $6.0 \mathrm{mg} / \mathrm{L}$. Four VAS plates were inoculated per test sample to provide duplicate plates for the two temperature zones used for isolation. To obtain an inoculum with $10^{4} \mathrm{CFU}$ following isolation, standardized ( $0.5 \mathrm{McFarland})$ inoculum was diluted by transferring $10 \mu \mathrm{L}$ of the standardized inoculum into $900 \mu \mathrm{L}$ of sterile normal saline. VAS test plates were then inoculated with a $10 \mu \mathrm{L}$ drop of the diluted inoculum by using a micropipette to deliver onto the agar surface, spotting an area of $10 \mathrm{~mm}$ to 15 $\mathrm{mm}$ at the centre of the VAS plate. As soon as they were inoculated, one set of duplicate plates was incubated at $30^{\circ} \mathrm{C}$. The second set of duplicate plates was incubated at $35^{\circ} \mathrm{C}$. All VAS plates were incubated for 24 hours and examined carefully for evidence of small colonies (>1 colony) or a film of growth, suggesting reduced susceptibility to vancomycin.

\subsection{Gene Detection by PCR}

PCR was performed following a recent PCR assay targeting $235 \mathrm{bp}$ marker within the vanA gene encoding staphylococcal vancomycin resistance [12]. Briefly, an aliquot $(0.5 \mathrm{~mL})$ of 0.5 McFarland standardized bacterial suspension was heated for $10 \mathrm{~min}$ at $95^{\circ} \mathrm{C}$. Following centrifugation (13000 RPM, $20 \mathrm{~s})$, the supernatant was used as template DNA for PCR amplification on an Eppendorf Mastercycler (Eppendorf, Hamburg, Germany). An initial single cycle for $4 \mathrm{~min}$ at $94^{\circ} \mathrm{C}$ was followed by 40 polymerization cycles consisting of $15 \mathrm{~s}$ at $94^{\circ} \mathrm{C}$ and $10 \mathrm{~s}$ at $60^{\circ} \mathrm{C}$ with a final polymerization at $72^{\circ} \mathrm{C}$ for $1 \mathrm{~min}$ and cooling at $8^{\circ} \mathrm{C}$ before gel electrophoresis. PCR products were resolved by horizontal submarine electrophoresis (Bio-Rad, USA) at $200 \mathrm{~V}$ for $30 \mathrm{~min}$ in Agarose gel (2\%) containing ethidium bromide $(0.5 \mu \mathrm{g} / \mathrm{mL})$. Following visualization (UV-transilluminator: UVP, Cambridge, UK), gel images were captured with the associated Vision Works ${ }^{\text {TM }}$ software. To obtain clean DNA for sequencing, PCR products were purified from Agarose gels using Gen Elute $^{\mathrm{TM}}$ according to the manufacturer (Sigma, UK). Sequencing reactions were prepared following the Applied Biosystems Big Dye ${ }^{\mathrm{TM}}$ 
protocol. Sequencing reaction was analyzed in a Prism 310 Genetic analyzer (Abbott Laboratories, USA) following which the obtained sequence data was followed by BLAST.

To allow for direct blind comparison of independent tests, PCR detection of vanA marker from the isolates was performed simultaneously without waiting for VAS to complete. In the end, both VAS and PCR results were examined together to confirm corroboration and/or discrepancies.

\section{RESULTS AND DISCUSSION}

\subsection{Concordance between vanA PCR and Identification of VRSA by VAS}

All $(100 \%)$ of the 48 control staphylococcal strains listed in Table 1 showed absolute concordance between vanA PCR and VAS methods. Following on this concordance which is important to ascertain assay accuracy, the collected samples revealed $22(14.2 \%)$ strains of the $155 \mathrm{~S}$. aureus isolates were VRSA while the remaining 131 strains were VSSA (Fig. 1).

All the strains identified as VRSA by VAS tested positive for vanA gene. vanA-negative strains did not grow on the vancomycin $(6 \mathrm{mg} / \mathrm{L})$ agar used for VAS. These findings are nosurprises as the 235 bp vanA PCR yielded 100\% positive predictive values (100\% PPV) and $100 \%$ negative predictive value (100\% NPV) when it was developed [12]. Several reports show varied levels of correlation between gene detection and agar-based identification of staphylococcal vancomycin-resistant phenotype. In India, report of staphylococcal isolates which expressed vancomycin resistance phenotypically for which detection of vanA and vanB genes by PCR was not possible had been published [13]. Failure of PCR to detect the genes encoding vancomycin resistance could be multifactorial ranging from poor priming to absence of the target gene (or sequence) within the genome. However, in another report from India, Saha et al. [14] documented what was described as the first successful recovery of VRSA by PCR as well as agar-based phenotypic methods.

\subsection{Monthly Frequencies of VRSA}

Between April 2013 and May 2014, 784 samples were collected for this study and $S$. aureus was isolated from $155(19.8 \%)$ samples (Table 2).

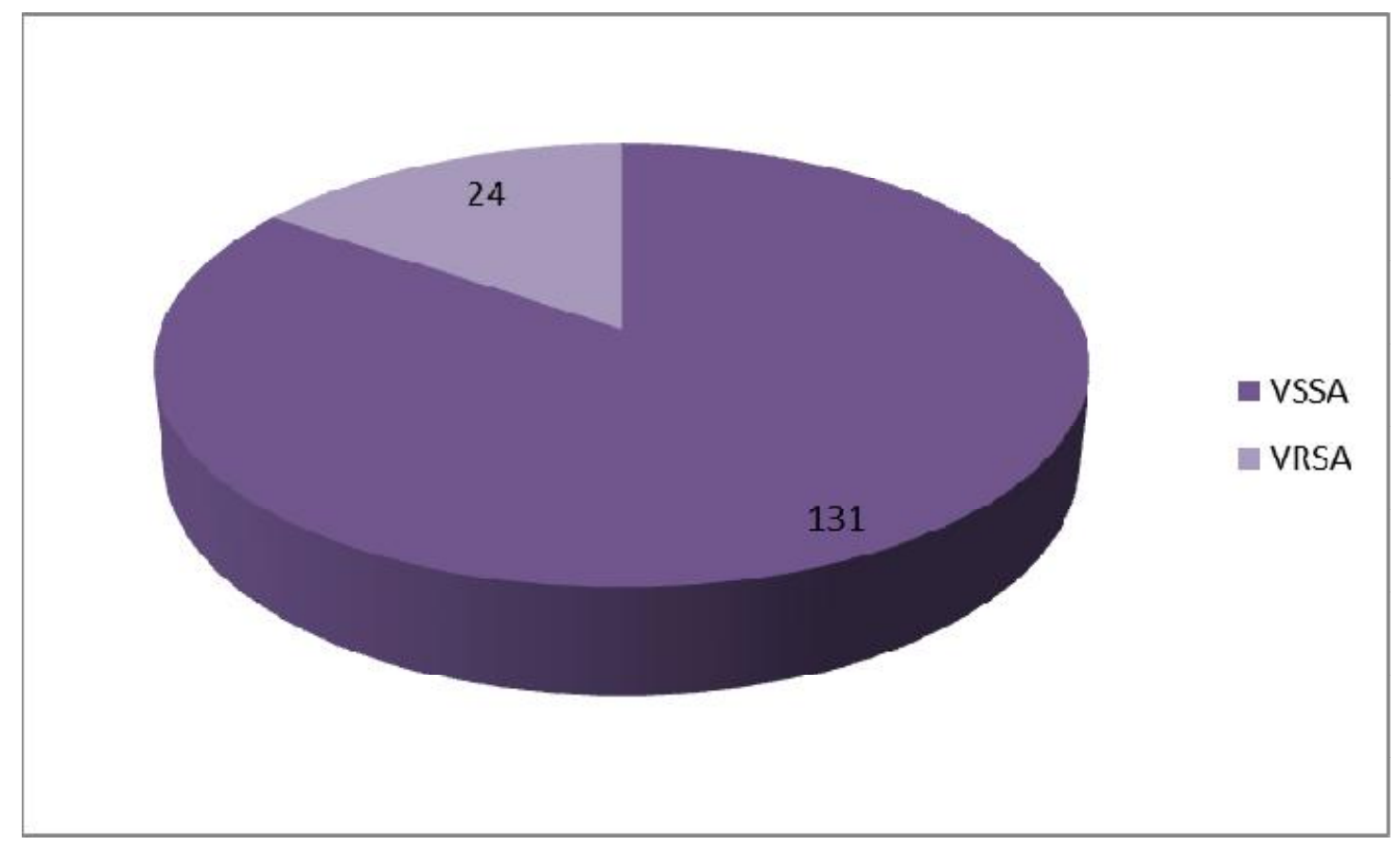

Fig. 1. Abundance of Staphylococcus aureus and VRSA recovered in the study 
Table 2. Monthly prevalence of $S$. aureus and VRSA isolates from poultry carcasses

\begin{tabular}{llll}
\hline $\begin{array}{l}\text { Month of } \\
\text { experimentation }\end{array}$ & $\begin{array}{l}\text { Number of } \\
\text { samples } \\
\text { collected }\end{array}$ & \multicolumn{2}{c}{$\begin{array}{l}\text { Number (\%) } \\
\text { positive for }\end{array}$} \\
\cline { 3 - 4 } & & $\begin{array}{l}\text { For } \\
\text { S. aureus }\end{array}$ & $\begin{array}{l}\text { For } \\
\text { VRSA }\end{array}$ \\
\hline 2013 April & 48 & $4(14.6)$ & $1(2.1)$ \\
2013 May & 55 & $10(18.2)$ & $2(3.6)$ \\
2013 June & 62 & $7(11.3)$ & $2(3.2)$ \\
2013 July & 65 & $10(15.4)$ & $3(4.6)$ \\
2013 August & 58 & $10(17.2)$ & $2(3.4)$ \\
2013 September & 54 & $11(20.4)$ & $2(3.7)$ \\
2013 October & 58 & $11(19.0)$ & $0(0.0)$ \\
2013 November & 57 & $14(24.6)$ & $3(5.3)$ \\
2013 December & 52 & $15(28.8)$ & $1(1.9)$ \\
2014 January & 55 & $9(16.4)$ & $1(1.8)$ \\
2014 February & 54 & $11(20.4)$ & $1(1.9)$ \\
2014 March & 54 & $15(27.8)$ & $2(3.7)$ \\
2014 April & 58 & $11(19.0)$ & $2(3.4)$ \\
2014 May & 54 & $17(31.5)$ & $2(3.7)$ \\
\hline
\end{tabular}

Although our findings show low prevalence of VRSA compared with the Zaria study which reported $46.2 \%$ VRSA [9], it still calls for attention in the use of antibiotics in animal production. Despite the efforts of the National Agency for Food and Drug Administration and Control (NAFDAC) especially in human drug (mis) use, it seems that more effort needs to be applied to the regulation of drug use in food animal production. However, given the low level of hygiene in poor settings

(http://www.who.int/water sanitation health/hygi ene/en/), of which this part of Nigeria is not excluded, the VRSA could also be of origins other than food animal production. It could even be one of the repercussions of poor hygiene.

\section{CONCLUSION}

Studies of Staphylococcus aureus isolates from retail chicken carcasses have been reported elsewhere, most of which showed varying levels of resistance to antibiotics including methicillin [15-17]. The report of $46.2 \%$ VRSA in Zaria chickens by Otaluetal (2011) is probably the first in Nigeria. Whether they originate from poor hygiene or from uncontrolled and indiscriminate sale and use of antibiotics as the authors mentioned, larger scale testing for the presence of antibiotic resistance especially VRSA in animals is recommended. As VRSA in humans is not widespread at the moment, the possibility of inter-species transmission of $S$. aureus, makes the recommendation for further investigations imperative.

\section{COMPETING INTERESTS}

Authors have declared that no competing interests exist.

\section{REFERENCES}

1. Shoji M, Cui L, lizuka R, Komoto A, Neoh $\mathrm{H}$, Watanabe $\mathrm{Y}$, et al. walK and clpP Mutations Confer Reduced Vancomycin Susceptibility in Staphylococcus aureus. Antimicrob Agents Chemother. 2011;55(8):3870-81.

2. Gardete S, Kim C, Hartmann BM, Mwangi M, Roux CM, Dunman PM, et al. Genetic Pathway in Acquisition and Loss of Vancomycin Resistance in a Methicillin Resistant Staphylococcus aureus (MRSA) Strain of Clonal Type USA300. PLoS Pathog. 2012;8(2):e1002505.

3. Kobayashi SD, Musser JM, De Leo FR. Genomic analysis of the emergence of vancomycin-resistant Staphylococcus aureus. mBio. 2012;3(4):e00170-12.

4. Rossi F, Diaz L, Wollam A, Panesso D, Zhou Y, Rincon S, et al. Transferable vancomycin resistance in a communityassociated MRSA lineage. $\mathrm{N}$ Engl $\mathrm{J}$ Med. 2014;370(16):1524-31.

5. Howden BP, Davies JK, Johnson PDR, Stinear TP, Grayson ML. Reduced Vancomycin Susceptibility in Staphylococcus aureus, Including Vancomycin-Intermediate and Heterogeneous Vancomycin-Intermediate Strains: Resistance Mechanisms, Laboratory Detection, and Clinical Implications. ClinMicrobiol Rev. 2012;23(1):99-139.

6. Winstanley T, Courvalin P. Expert systems in clinical microbiology. Clin. Microbiol. Rev. 2011;24(3):515-56.

7. Food and Agricultural Organization. Poultry Sector Country Review (Nigeria). FAO Animal Production and Health Division, Food and Agricultural Organization of the United Nations, Rome; 2008.

8. Friese $A$, Schulz J, Zimmermann K, Tenhagen B-A, Fetsch A, Hartung J, et al. Occurrence of Livestock-Associated Methicillin-Resistant Staphylococcus aureus in Turkey and Broiler Barns and Contamination of Air and Soil Surfaces in Their Vicinity. Appl. Environ. Microbiol. 2013;79(8):2759-66. 
9. Otalu O Jr, Kabir J, Okolocha EC, Umoh VJ. Multi-drug Resistant Coagulase Positive Staphylococcus aureus from Live and Slaughtered Chickens in Zaria, Nigeria. International Journal of Poultry Science. 2011;10(11):871-5.

10. Persoons D, Van Hoorebeke S, Hermans K, Butaye $P$, de Kruif A, Haesebrouck F, et al. Methicillin-resistant Staphylococcus aureus in poultry. Emerg Infect Dis. 2013;15(3):452-3.

11. Clinical and Laboratory Standards Institute. Performance Standards for Antimicrobial Disk and Dilution Susceptibility Tests for Bacteria Isolated From Animals. Clinical and Laboratory Standards Institute. Approved Standard - Third Edition. Wayne, PA; 2008.

12. Okolie CE, Cockayne A, Wooldridge $\mathrm{K}$, James $\mathrm{R}$. Development and validation of a new diagnostic PCR assay for vanA gene encoding vancomycin resistance in Staphylococcus aureus. IJAMBR. 2014;2:1-10.

13. Tiwari HK, Sen MR. Emergence of vancomycin resistant $S$. aureus (VRSA) from a tertiary care hospital from northern part of India. BMC Infect Dis. 2006;6:156.

14. Saha B, Singh AK, Ghosh A, Bal M. Identification and characterization of a vancomycin-resistant $S$. aureus isolated from Kolkata (South Asia). J Med Microbiol. 2008;57(1):72-9.

15. Lin J, Yeh KS, Liu HT, Lin JH. Staphylococcus aureus isolated from pork and chicken carcasses in Taiwan: prevalence and antimicrobial susceptibility. J Food Prot; 2009;72(3):608-611.

16. Hanning I, Gilmore D, Pendleton S, Fleck $\mathrm{S}$, Clement A, Park SH, et al. Characterization of Staphylococcus aureus isolates from retail chicken carcasses and pet workers in Northwest Arkansas. J Food Prot. 2012;75(1):174-8.

17. Momtaz H, Dehkordi FS, Rahimi E, Asgarifar A, Momeni M. Virulence genes and antimicrobial resistance profiles of Staphylococcus aureus isolated from chicken meat in Isfahan province, Iran. J Appl Poult Res. 2013;22(4):913-21.

(c) 2015 Okolie et al.; This is an Open Access article distributed under the terms of the Creative Commons Attribution License (http://creativecommons.org/licenses/by/4.0), which permits unrestricted use, distribution, and reproduction in any medium, provided the original work is properly cited.

Peer-review history:

The peer review history for this paper can be accessed here: http://www.sciencedomain.org/review-history.php?iid=806\&id=11\&aid=8040 